\title{
Determinants of alcohol use and khat chewing among Hawassa University students, Ethiopia: a cross sectional study.
}

\author{
Andargachew Kassa ${ }^{1}$, Negash Wakgari ${ }^{1}$, Fiker Taddesse ${ }^{2}$
}

1. School of Nursing and Midwifery, College of Medicine and Health Sciences, Hawassa University, Hawassa, Ethiopia

2. School of Medicine, Pharmacology Unit, College of Medicine and Health Sciences, Hawassa University, Hawassa, Ethiopia

\begin{abstract}
Background: Students' alcohol and khat use have been associated with various health related problems. However, its magnitude and associated factors among Ethiopian students are not yet well documented.

Objective: The study aimed to assess the prevalence of alcohol use, khat chewing and its associated factors among Hawassa University students.

Methods: A cross-sectional study was conducted from June to July 2011. Multistage stratified sampling technique was employed to select 590 students. Self administered questionnaires were used to collect data. Data was entered and analysed by SPSS version 20.0. Logistic regression analyses were used to identify the association of different variables.

Results: The current prevalence of student's alcohol and khat use were 29.5\% (95\% CI: 25.8-33.3) and 16.3\% (95\% CI: 13.720.0) respectively. Being male (AOR 1.8; 95\% CI 1.1-3.0) and living alone (AOR 20.1; 95\% CI 2.5-166.7) had a higher odds of alcohol use. Similarly, family substance use history (AOR 4.8; 95\% CI 2.5-9.3) and peer influence (AOR 4.6; 95\% CI 2.3-9.0) had also higher odds of khat use.

Conclusion and recommendation: The proportion of student's khat chewing and alcohol use was significant. Hence, higher education in collaboration with other stakeholders should work on convincing students about the ill effects of these substances. Keywords: Alcohol use, cigarette smoking, university students, substance use, khat chewing.

DOI: http://dx.doi.org/10.4314/ahs.v16i3.24

Cite as: Kassa A, Wakgari N, Taddesse F. Determinants of alcohol use and khat chewing among Hawassa University students, Ethiopia: a cross sectional study. Afri Health Sci 2016;16(3): 822-830. DOI: http:// dx.doi.org/10.4314/abs.v16i3.24
\end{abstract}

\section{Background}

Alcohol and khat are the most widely used psychoactive substances in the world ${ }^{1,2}$. In 2004, World Health Organization's report on Global strategy to reduce harmful use of alcohol revealed that globally about $4 \%$ of all deaths are contributed by alcohol consumption. The document further stated that every year, harmful use of alcohol kills about 2.5 million people ${ }^{3}$. About half of all alcohol
Corresponding author:
Andargachew Kassa,
Telephone: +2519-1133-8895
Fax number: +046-220-8755
P.O. Box:1650, Hawassa, Ethiopia
E-mail address: akandkassa@gmail.com,
andkassa@hu.edu.et

African Health Sciences Vol 16 Issue 3, September 2016 consumption is in Africa ${ }^{1}$. Alcohol use is associated with poor health, social costs, decreased academic performance, increased risk of contracting sexually transmitted diseases, or other psychiatric disorders such as lethargy, hopelessness, and insomnia ${ }^{3-5}$.

Khat is a commonly used natural stimulant from the Catha edulis plant at the Southern part of the Arabian penisula and East Africa ${ }^{6-8}$. Khat chewing is believed to alter one's mood or emotional state by prolonging the activities of neurotransmitters such as dopamine and norepinephrine in the brain, thereby enhancing the response of the individual. Its effects are increased self esteem, increased levels of energy, increased libido and excitement ${ }^{9-11}$. Different studies revealed that frequent khat chewing has been associated with risky sexual behavior, predisposition to HIV, unwanted pregnancy, reduced school performance, adverse pregnancy outcome, and cardiovascular disorders $^{12-16}$. 
In developing countries only few families can afford the expenses for alcohol use and khat chewing for college students that initiates them to be engaged in crime. Similarly, khat chewers have less interest to work, and this has an impact on their economic status and social interaction $^{17}$.

The literature suggest that peer influence, family factors and personal background play the important role in the development of youth substance use behavior $^{18-20}$. Investigating University students alcohol use and khat chewing,and its associated factors has a paramount significance for policy makers, university officials and researchers to design effective strategy which can reduce the students substance use and its' associated sequels ${ }^{21}$. However, few studies have investigated the prevalence of alcohol use, khat chewing and its determinant factors among University students in Ethiopia ${ }^{17,21,25}$. Hence, this study aimed to assess the prevalence of alcohol use, khat chewing and its associated factors among Hawassa University students, Hawassa, Ethiopia.

\section{Methods}

An institution-based cross-sectional study was conducted from June to July, 2011 to assess the prevalence and factors associated with alcohol use and khat chewing among students of Hawassa University, Ethiopia. Four campuses of the university were involved: Main campus, College of medicine and health sciences campus, Agricultural campus and Wondogenet Forestry campus. During the study period, the University had a total of 15,104 undergraduate students enrolled in 58 academic departments. These students came from all regions of Ethiopia. All regular undergraduate students attending the four colleges of the University were considered as the source population.

The sample size was calculated using single population proportion formula: The proportion $(\mathrm{p})=22.0 \%$ (21), $95 \%$ confidence level of $\mathrm{Za} / 2=1.96,5 \%$ of absolute precision. With a non response rate of $12 \%$ and a design effect of two for multistage sampling, the total sample size was 590 .

The study participants were selected using a multistage stratified sampling technique. During the first stage, from a total of 58 departments twenty five departments were selected by using simple random sampling technique. In the second stage, departments in each field of study were further stratified by years of study and sex, on the assumption that duration of stay in the campus and sex would affect alcohol use and khat chewing. The total sample size was distributed proportionally to the selected departments based on total number of students in each year of study according to sex. Finally, individual students fulfilling the inclusion criterion were randomly selected as study participants.

Relevant literature was reviewed to develop the tool and to include all the possible variables that address the objective of the study ${ }^{22-24}$. The questionnaire was first prepared in English and then translated into the local language (Amharic), and back into English to maintain conceptual consistency. A pre- test was conducted on 30 students at Dilla University. Findings from the pre-test were used to modify the instrument.

The collected data was cleaned, coded, entered and analyzed using SPSS version 20. Descriptive and summary statistics were done. Both bivariate and multivariate logistic regression analysis was used to determine the association of each independent variable with the dependent variable. The outcome variables, alcohol and khat consumption were categorical with Yes/No response which follows binomial distribution. Then the effect of the covariates such as sex, academic year, living status during school age, parent's educational level, family substance use history, peer influence, family pressure, other substance use history, monthly pocket money, and coming from an orphanage center was investigated.

Odds ratio was computed at $95 \%$ confidence interval to identify the presence and strength of association. To minimize the effect of confounding, stratification was done by variables which were assumed to have confounding effect. In addition, multivariate analysis was used to control confounding variables. Those variables which showed statistically significant association in bivariate analysis and main variables which could have an effect on the outcome were also included in the multivariate model. Moreover, a stratified analysis were done to check for interaction terms or presence of confounding variable using the Cochran-Mantel-Haenszel test. 
The operational definitions given to the most important variables were defined as follows:

- "Lifetime alcohol and khat use" were defined as respondents who admitted to having ever used alcohol and khat, respectively.

- "Past twelve month alcohol and khat uses" were defined as students who use alcohol and khat in the 12 months prior to the date of data collection respectively.

- "Current prevalence of alcohol and khat uses" were defined as the proportion of students who used alcohol and khat within 30 days preceding the study respectively.

Ethical clearance was obtained from Institutional Review Board of the College of Medicine and Health Sciences, Hawassa University. To ensure voluntary participation of the participants, a written and signed informed consent was obtained from each student. After informing each respondent about the aim and purpose of the study, participants were asked for their vol- untary participation. Those respondents were assured for their right to withdraw from the study anytime if they felt unhappy. Additionally, the confidentiality of the data was ensured by using anonymous questionnaire and by storage of the data in a safe and protected place.

\section{Results}

Socio-demographic characteristics of the study participants

A total of 590 participants were included in the study (response rate $=94.5 \%)$. The majority, $479(81.7 \%)$, of the study subjects were male and $468(69.2 \%)$ were $20-24$ years of age. Their mean age was 20.7 years (Standard Deviation $(\mathrm{SD})=1.49)$. Three hundred fifty $(59.7 \%)$ of them were Orthodox by religion, followed by Protestants $(25.1 \%)$. Regarding ethnicity of study participants, the largest proportion belongs to Amhara 186 (31.7\%) followed by Oromo $(20.2 \%)$, Tigre $(11.4 \%)$, Wolaita $(6.6 \%)$, and Sidama (2.9\%) (Table 1).

Table1: Socio-demographic characteristics of Hawassa University students, June/July, 2011

\begin{tabular}{|c|c|c|c|}
\hline Variables & \multicolumn{2}{|r|}{ Sex } & Total N (\%) \\
\hline \multicolumn{4}{|l|}{ Age group( years) } \\
\hline $15-19$ & $72(12.3 \%)$ & $34(5.8 \%)$ & $106(18.1 \%)$ \\
\hline $20-24$ & $397(67.8 \%)$ & $71(12.1 \%)$ & $468(79.9 \%)$ \\
\hline $25-30$ & $10(1.7 \%)$ & $2(0.3 \%)$ & $12(2.0 \%)$ \\
\hline Total & $479(81.8 \%)$ & $107(18.2 \%)$ & $586(100 \%)$ \\
\hline \multicolumn{4}{|l|}{ Religion } \\
\hline Orthodox Christian & $285(48.6 \%)$ & $65(11.1 \%)$ & $350(59.7 \%)$ \\
\hline Protestant Christian & $127(21.7 \%)$ & $29(4.9 \%)$ & $156(26.6 \%)$ \\
\hline Muslim & $53(9.0 \%)$ & $9(1.5 \%)$ & $62(10.6 \%)$ \\
\hline Others & $14(2.4 \%)$ & $4(0.7 \%)$ & $18(3.1 \%)$ \\
\hline Total & $479(81.8 \%)$ & $107(18.3 \%)$ & $586(100 \%)$ \\
\hline \multicolumn{4}{|l|}{ Year of education } \\
\hline Year I & $195(33.2 \%)$ & $48(8.2 \%)$ & $243(41.3 \%)$ \\
\hline Year II & $115(19.6 \%)$ & $30(5.1 \%)$ & $145(24.7 \%)$ \\
\hline Year III & $148(25.2 \%$ & $23(3.9 \%$ & $171(29.1 \%)$ \\
\hline Year IV & $13(2.2 \%)$ & $3(0.5 \%)$ & $16(2.7 \%)$ \\
\hline Year V & $5(0.9 \%)$ & $2(0.3 \%)$ & $7(1.2 \%)$ \\
\hline Year VI/ Internship & $3(0.5 \%)$ & $1(0.2 \%)$ & $4(0.7 \%)$ \\
\hline Total & $479(81.4 \%)$ & $107(18.2 \%)$ & $586(100 \%)$ \\
\hline \multicolumn{4}{|l|}{ Mother's educational level } \\
\hline Illiterate & $192(32.6 \%)$ & $14(2.4 \%)$ & $206(35.2 \%)$ \\
\hline Elementary to Grade 12 & $202(34.3 \%)$ & $54(9.2 \%)$ & $256(43.5 \%)$ \\
\hline College or University & $69(11.7 \%)$ & $38(6.5 \%)$ & $107(18.2 \% 0$ \\
\hline Do not know & $16(2.7 \%)$ & $1(0.2 \%)$ & $17(2.9 \%)$ \\
\hline Total & $479(81.4 \%)$ & $107(18.2 \%)$ & $586(100 \%)$ \\
\hline \multicolumn{4}{|l|}{ Father's educational level } \\
\hline Illiterate & $118(20.1 \%)$ & $8(1.4 \%)$ & $126(21.5 \%)$ \\
\hline Elementary to Grade 12 & $228(38.9 \%)$ & $44(7.5 \%)$ & $272(46.4 \%)$ \\
\hline College or University & $114(19.5 \%)$ & $52(8.9 \%)$ & $166(28.3 \%)$ \\
\hline Do not know & $19(3.2 \%)$ & $3(0.5 \%)$ & $22(3.8 \%)$ \\
\hline Total & $479(81.7 \%)$ & $107(18.3 \%)$ & $586(100 \%)$ \\
\hline
\end{tabular}


Magnitude of alcohol use and khat chewing The overall lifetime and past 12-month prevalence of alcohol use among the study subjects were $285(48.7 \%$, CI:44.4 - 52.6) and 239 (40.8\%, CI: 37.0 - 44.8) respec- tively. The life time and past 12 month prevalence of khat chewing were 141 (24.1\% CI: 20.9 - 27.8) and $119(20.3 \%$ CI: 17.2 - 23.8) (Table 2).

Table 2: The life time, last 12 month and current prevalence of alcohol and khat use among Hawassa University students $(n=586)$ June/July, 2011

\begin{tabular}{|c|c|c|c|c|c|c|}
\hline \multirow{2}{*}{$\begin{array}{l}\text { Type of substances } \\
\text { used }\end{array}$} & \multicolumn{2}{|c|}{ Total $(n=586)$} & \multicolumn{2}{|c|}{ Male } & \multicolumn{2}{|c|}{ Female } \\
\hline & Frequency & Percent & Frequency & Percent & Frequency & Percent \\
\hline Ever drunk alcohol & 285 & $48.7 \%$ & 251 & $88.1 \%$ & 34 & $11.9 \%$ \\
\hline $\begin{array}{l}\text { Drunk alcohol in the } \\
\text { past } 12 \text { months } \\
\text { Drunk alcohol in the }\end{array}$ & 239 & $40.8 \%$ & 208 & $87.0 \%$ & 31 & $12.9 \%$ \\
\hline Past 30 days & 173 & $29.5 \%$ & 148 & $85.5 \%$ & 25 & $14.4 \%$ \\
\hline Ever chewed khat & 141 & $24.1 \%$ & 129 & $91.5 \%$ & 12 & $8.5 \%$ \\
\hline $\begin{array}{l}\text { Chewed khat in the } \\
\text { past } 12 \text { months } \\
\text { Chewed khat in the }\end{array}$ & 119 & $20.3 \%$ & 108 & $90.8 \%$ & 11 & $9.3 \%$ \\
\hline past 30 days & 98 & $16.3 \%$ & 89 & $90.8 \%$ & 9 & $9.2 \%$ \\
\hline
\end{tabular}

The current prevalence of student's alcohol and khat use were $29.5 \%$ (CI:25.8-33.3) and 16.3\% (CI: 13.7-20.0) respectively. The mean ages at which the respondents started drinking alcohol and chewing khat were 15.4 years (SD \pm 3.5 years) and 16.6 years (SD \pm 2.7 years) respectively.
The respondents also reported different problems that they encountered due to alcohol consumption and other psychoactive substances. Fifty eight $(20.4 \%)$ of them had an argument with their friends whereas $24(8.5 \%)$ engaged in unprotected sex after having alcohol (Table 3).

Table 3: Reported problems of Hawassa University students due to their alcohol use $(n=285)$ or other psychoactive substance use $(n=315)$. June /July 2011

\begin{tabular}{|c|c|c|}
\hline Questions & $\begin{array}{l}\text { Yes because of my } \\
\text { alcohol use }\end{array}$ & $\begin{array}{l}\text { Yes because of my } \\
\text { other psychoactive } \\
\text { substance use }\end{array}$ \\
\hline Have you ever had a quarrel or argument? & $58(20.4 \%)$ & $31(19.3 \%)$ \\
\hline Have you ever had a scuffle or fight? & $50(17.6 \%)$ & $21(13.0 \%)$ \\
\hline Have you ever had an accident or injury? & $19(6.7 \%)$ & $20(12.4 \%)$ \\
\hline $\begin{array}{l}\text { Have you ever lost money or other valuable } \\
\text { items? }\end{array}$ & $47(16.5 \%)$ & $22(13.7 \%)$ \\
\hline $\begin{array}{l}\text { Have you ever had damage to objects or } \\
\text { clothing? }\end{array}$ & $45(15.8 \%)$ & $27(16.8 \%)$ \\
\hline $\begin{array}{l}\text { Have you ever had problems in your relationship } \\
\text { with your parents? }\end{array}$ & $34(11.9 \%)$ & $19(11.8 \%)$ \\
\hline with your friends? & $29(10.3 \%)$ & $23(14.3 \%)$ \\
\hline $\begin{array}{l}\text { with your teachers? } \\
\text { Have you ever had performed poorly at school or }\end{array}$ & $13(04.6 \%)$ & $14(08.7 \%)$ \\
\hline $\begin{array}{l}\text { work? } \\
\text { Have you ever been a victim of robbery or theft? }\end{array}$ & $27(09.5 \%)$ & $34(14.9 \%)$ \\
\hline & $20(07.0 \%)$ & $12(07.5 \%)$ \\
\hline Have you ever had trouble with police? & $26(09.2 \%)$ & $08(05.0 \%)$ \\
\hline $\begin{array}{l}\text { Have you ever been hospitalized or admitted to } \\
\text { an emergency room? }\end{array}$ & $16(05.6 \%)$ & $13(08.1 \%)$ \\
\hline $\begin{array}{l}\text { Have you ever been engaged in sex you regretted } \\
\text { the next day? } \\
\text { Have you ever engaged in unprotected sex? }\end{array}$ & $\begin{array}{l}30(10.6 \%) \\
24(8.5 \%)\end{array}$ & $\begin{array}{l}11(06.8 \%) \\
09(06.0 \%)\end{array}$ \\
\hline
\end{tabular}


Factors associated with alcohol use

In the bivariate analysis the factors found to be significantly associated with alcohol use were: sex, academic year, living alone during school age, mothers' educational status, family history of substance use, peer influence, family pressure, smoking, khat chewing, and marijuana and shisha use. However, in the multiple logistic regression analysis: sex, living alone during school age, and mother's educational status were significantly associated with the prevalence of alcohol use. Being a male was about 2 times more likely to be associated with alcohol consumption than being a female $(\mathrm{AOR}=1.8,95 \% \mathrm{CI}: 1.0$,
3.0). Those students who lived alone during the school age were 20.2 times more likely to have alcohol consumption than those who lived with their family (AOR $=20.1$, 95\% CI: 2.5, 166.7).

Similarly, students whose mother's educational status was high school and above were about 2 times more likely to have alcohol use than those whose mother's educational status was below high school $(A O R=1.6,95 \%$ CI:1.0, 2.5). In addition, ever smoked (AOR $=3.8,95 \%$ CI: 1.9, 7.7) and ever used khat (AOR $=3.9,95 \% \mathrm{CI}: 2.3$, 6.6) were significantly associated with alcohol use than their referent group (Table 4).

\section{Table 4: Bivariate and multivariate logistic regression analysis showing socio-demographic and behavioral correlates of alcohol use within the last 12 months among Hawassa University students, June /July 2011}

\begin{tabular}{|c|c|c|c|c|c|}
\hline \multirow[t]{2}{*}{ Variables } & & \multicolumn{2}{|c|}{$\begin{array}{l}\text { Used } \\
\text { Alcohol }\end{array}$} & \multirow[t]{2}{*}{$\begin{array}{l}\text { COR } \\
(95.0 \% \text { CI })\end{array}$} & \multirow[t]{2}{*}{ AOR $(95.0 \%$ CI) } \\
\hline & & Yes & No & & \\
\hline \multirow[t]{2}{*}{ Sex } & Male & 208 & 271 & $1.9(1.2-3.0)$ & $1.8(1.1-3.0)$ \\
\hline & Female & 31 & 76 & 1 & 1 \\
\hline \multirow{2}{*}{$\begin{array}{l}\text { Academic year two and } \\
\text { above }\end{array}$} & Yes & 157 & 82 & $1.7(1.2-2.3)$ & $1.5(0.9-2.2)$ \\
\hline & No & 186 & 161 & 1 & 1 \\
\hline \multirow{2}{*}{$\begin{array}{l}\text { Lived alone during school } \\
\text { age: }\end{array}$} & Yes & 9 & 1 & $13.5(1.7-107.6)$ & $20.1(2.5-166.7)$ \\
\hline & No & 230 & 346 & 1 & 1 \\
\hline \multirow{2}{*}{$\begin{array}{l}\text { Mothers education high } \\
\text { school and above }\end{array}$} & Yes & 88 & 100 & $1.4(1.0-2.0)$ & $1.63(1.1-2.5)$ \\
\hline & No & 151 & 247 & 1 & 1 \\
\hline \multirow{2}{*}{$\begin{array}{l}\text { Family of substance use } \\
\text { history: }\end{array}$} & Yes & 52 & 302 & $2.0(1.2-3.0)$ & $1.2(0.7-2.0)$ \\
\hline & No & 187 & 45 & 1 & 1 \\
\hline \multirow[t]{2}{*}{ Peer influence } & Yes & 50 & 307 & $2.0(1.3-3.2)$ & $1.2(0.7-2.1)$ \\
\hline & No & 189 & 40 & 1 & 1 \\
\hline \multirow[t]{2}{*}{ Family pressure } & Yes & 7 & 232 & $3.5(0.9-13.5)$ & $3.1(0.6-14.8)$ \\
\hline & No & 344 & 3 & 1 & 1 \\
\hline \multirow{2}{*}{ Ever used marijuana } & Yes & 10 & 229 & $5.0(1.4-18.4)$ & $1.3(0.3-6.8)$ \\
\hline & No & 3 & 344 & 1 & 1 \\
\hline \multirow[t]{2}{*}{ Ever used shisha } & Yes & 45 & 9 & $8.7(4.2-18.2)$ & $1.8(0.7-4.6)$ \\
\hline & No & 194 & 338 & 1 & 1 \\
\hline
\end{tabular}

$1=$ Reference

\section{Factors associated with khat chewing}

In the bivariate analysis the factors found to be significantly associated with alcohol use were: sex, academic year, monthly pocket money, being brought up in orphanage center, father's educational status, family substance use history, peer influence, family pressure, ever smoked, ever used alcohol, and marijuana. However, according to the multiple logistic regression analysis sex, family substance use history, peer influence, ever smoked, ever used alcohol and shisha, were significantly associated with khat chewing. The males were five times more likely to chew khat than the females (AOR $=4.9,95 \% \mathrm{CI}$ : 1.6, 15.8).
Those students who had family history of substance use were about five times more likely to chew khat than the students who had no family history of substance use $(\mathrm{AOR}=4.8,95 \% \mathrm{CI}: 2.5,9.3$ ). Similarly, having a friend who used khat increased the odds of khat chewing by 4.6 times $(\mathrm{AOR}=4.6,95 \% \mathrm{CI}: 2.3,9.0)$. Most importantly, ever using shisha increased the risk of khat chewing by 32.1 fold, (AOR=32.1, 95\% CI: 10.7, 96.3).

Similarly, ever smoked increased the risk of khat chewing by seven fold(AOR=6.9, 95\% CI: 3.3, 14.4). Having used alcohol is another factor that increased the risk of having khat chewing by three times (AOR $=3.2,95 \% \mathrm{CI}: 1.7,6.1)$ (Table 5). 
Table 5: Bivariate and multivariate logistic regression analysis showing socio-demographic and behavioral correlates of khat chewing within the last 12 months among Hawassa

University students, June /July 2011

\begin{tabular}{|c|c|c|c|c|c|}
\hline \multirow[t]{2}{*}{ Variables } & & \multicolumn{2}{|c|}{$\begin{array}{l}\text { Used } \\
\text { Alcohol }\end{array}$} & \multirow[t]{2}{*}{ COR (95.0\%CI) } & \multirow[t]{2}{*}{ AOR (95.0\% CI) } \\
\hline & & Yes & No & & \\
\hline \multirow[t]{2}{*}{$\overline{\text { Sex }}$} & Male & 108 & 371 & $2.5(1.3-4.9)$ & $4.9(1.6-15.8)$ \\
\hline & Female & 11 & 96 & $1 *$ & 1 \\
\hline \multirow{2}{*}{$\begin{array}{l}\text { Academic year two and } \\
\text { above }\end{array}$} & Yes & 81 & 262 & $1.7(1.1-2.6)$ & $1.2(0.6-2.2)$ \\
\hline & No & 38 & 205 & 1 & 1 \\
\hline \multirow[t]{2}{*}{ Reared in orphanage center } & Yes & 4 & 3 & $5.4(1.2-24.4)$ & $5.0(0.7-36.6)$ \\
\hline & No & 115 & 464 & 1 & 1 \\
\hline \multirow{2}{*}{$\begin{array}{l}\text { When students pocket } \\
\text { money } \geq 150.00 \text { ETB }\end{array}$} & Yes & 97 & 329 & $0.5(0.3-0.9)$ & $1.4(0.7-2.7)$ \\
\hline & No & 22 & 138 & 1 & 1 \\
\hline \multirow{2}{*}{$\begin{array}{l}\text { Family substance use } \\
\text { history: }\end{array}$} & Yes & 40 & 57 & $3.6(2.3-5.8)$ & $4.8(2.5-9.3)$ \\
\hline & No & 79 & 410 & 1 & 1 \\
\hline \multirow{2}{*}{$\begin{array}{l}\text { Father's education high } \\
\text { school and above }\end{array}$} & Yes & 72 & 214 & $1.8(1.2-2.7)$ & $1.2(0.7-2.3)$ \\
\hline & No & 47 & 253 & 1 & 1 \\
\hline \multirow[t]{2}{*}{ Peer influence } & Yes & 40 & 50 & $4.2(2.6-6.8)$ & $4.6(2.3-9.0)$ \\
\hline & No & 79 & 417 & 1 & 1 \\
\hline \multirow[t]{2}{*}{ Family pressure } & Yes & 4 & 6 & $2.7(0.7-9.6)$ & $0.5(0.0-3.2)$ \\
\hline & No & 115 & 461 & 1 & 1 \\
\hline \multirow[t]{2}{*}{ Ever smoked } & Yes & 63 & 24 & $20.7(12.0-35.9)$ & $6.9(3.3-14.4)$ \\
\hline & No & 56 & 443 & 1 & 1 \\
\hline \multirow[t]{2}{*}{ Ever used alcohol } & Yes & 95 & 144 & $7.5(4.5-12.6)$ & $3.2(1.7-6.1)$ \\
\hline & No & 24 & 323 & 1 & 1 \\
\hline \multirow[t]{2}{*}{ Ever used marijuana } & Yes & 9 & 4 & $9.5(2.9-31.3)$ & $1.0(0.1-10.3)$ \\
\hline & No & 110 & 463 & 1 & 1 \\
\hline
\end{tabular}

$1^{*}=$ Reference

\section{Discussion}

The magnitude of alcohol use in the present study was $40.8 \%$ with $95 \%$ confidence interval of (37.0 - 44.8). This finding is in line with the studies done in Haramaya University $(41.7 \%)^{25}$. However, it is higher than the study done in NorthWestern Ethiopia $(31.1 \%)^{26}$. The possible reason for this difference could be the difference in the study time and expansion of khat production. For instance, the study conducted in NorthWestern Ethiopia was before 15 years of age. Due to absence of longtuidinal studies, the pattern of increment of khat use may not be well justified. Nevertheless, the ever increasing production and marketing of khat lay a base for the existing consensus that the proportion of khat users is on an increase $e^{6,7,13,35}$.

The magnitude of khat chewing in the present study was $20.3 \%$ with $95 \%$ confidence interval of $(17.2-23.8)$. This finding is consistent with the studies done in Jazan region of Saudi Arabia $(20.5 \%)^{27},(23.1 \%)^{28},(21 . \%)^{29}$ and North West Ethiopia (17.5\%) (17) $(22.3 \%)^{30}$. This finding is nearly similar but slightly lower than a study conducted in Eastern Ethiopia $(24.2 \%)^{11}$. These differences might be due to the fact that Eastern Ethiopia is a high khat producing and exporting regions and also has places where khat use is socially acceptable. Moreover, the dominant religion in the area is Muslim which in comparison to other religions shows statistically significant association with khat use habit ${ }^{11,34}$.

The students who use alcohol reported that they ever had quarrel or argued with others 58(20.4\%), had scuffle or fight $50(17.6 \%)$, faced accident or injury $19(6.7 \%)$, were hospitalized or admitted to an emergency room $16(5.6 \%)$, performed poorly at school or work $27(9.5 \%)$, were involved in trouble with police $26(9.2 \%)$, engaged in

African Health Sciences Vol 16 Issue 3, September 2016 
sex they regretted the next day $30(10.6 \%)$, and were engaged in unprotected sex $24(8.5 \%)$. This is consistent with other findings that alcohol and other psycho actives substance use are associated with high rates of sexual risk taking, poor health, social costs, decreased academic performance, increased risk of contracting sexually transmitted diseases, and other psychiatric disor$\operatorname{ders}^{3-5}$.

The sex of the respondents remained a remarkable predictor that influences students' alcohol use. Being male had more likely hood to cause alcohol consumption by two fold than being female. This agrees with a studies conducted in Eastern Ethiopia ${ }^{31}$ and United State of America $^{32}$.

Similarly, students who lived alone during their school age were twenty times more likely to use alcohol than those who lived with their family. Parents can influence their children's attitude about alcohol use by close monitoring, being a role model, and giving information about the effects of alcohol use on their health and academic performance ${ }^{33}$. Hence, the students who lived alone during their school age missed the opportunity of getting these benefits from their parents.

Furthermore, the study found that mothers' educational status is another factor influencing student's alcohol use. Students whose mothers' educational status was high school and above were about 2 times more likely to have alcohol use than those whose mother's educational status was below high school. In most of the developing countries illiterate women are economically dependent. If their educational status is high school and above, there is a probability of economical independency; consequently that might improve the pocket money of their students which might be helpful in buying alcohol and khat easily. The other possible explanation could be traditionally among most Ethiopia females in rural areas drinking alcohol is not socially acceptable; currently which is a culture among educated females. Therefore, greater parental approval for drinking alcohol influences student's alcohol consumption ${ }^{33}$.

Being male was found to have positive association with khat chewing. This is in line with the previous studies $^{11,27-29,34,35}$. Smoking in life time and alcohol use in lifetime were also other important determinant factors for khat chewing in the current study. This also agrees with the study done in Jazan region of Saudi Arabia ${ }^{27,28}$ and Jimma town of Ethiopia ${ }^{34,35}$. In addition, history of family substance use remained another important factor for khat chewing by Hawassa University students ${ }^{11,27,36}$. Moreover, peer influence increased the odds of students' khat chewing by five fold. This is supported by different previous studies ${ }^{11,28,35}$.

Though this study is the first conducted among Hawassa University students, it is not without limitation. First, as the study is a cross-sectional, we could not establish causal relationship between the independent and outcome variables. Second, there may be some factors which determine students khat and alcohol use but not included in our study. Lastly, since the study is institution based, generalization of the findings of this study to all youths out of the university may not be appropriate.

\section{Conclusion and recommendation}

The prevalence of alcohol use and khat chewing among Hawassa University students was high. Being a male, living alone during the school age and mothers' educational status were found to be the factors affecting students' alcohol use. Similarly, being a male, family history of substance use history, peer influence, life time use of alcohol and smoking cigarette in life time were found to be the most important determinant factors for khat chewing. Higher education in collaboration with Regional Health Bureau, Ministry of Health and policy makers should work on awareness creation and convincing students about the ill effects of alcohol use and khat chewing. Longitudinal studies should be conducted to check reproducibility of alcohol use and khat chewing among Ethiopian University students. Moreover, designing an effective strategy focused on male students and orphans should be implemented.

\section{Competing interests}

We authors declare that we have no competing interests.

\section{Acknowledgements}

We are grateful to Hawassa University for funding this project, and students for participating in the study.

\section{Authors' contributions}

AKB: Conceived and designed the research study, de- 
veloped the proposal,and prepared the manuscript. NW participated in the analysis, drafted the manuscript and revised subsequent drafts of the paper. FT: Participated in the research proposal development and analysis. All authors read and approved the final manuscript.

\section{Authors' information}

(AKB)1: BSN, MSN,PHN,RN, Assistant Professor, Hawassa University, College of Medicine and Health sciences, School of Nursing and Midwifery, P.O. Box:1560, Hawassa, Ethiopia, +2519-1133-8895, akandkassa@gmail.com or andkassa@hu.edu.e

(NW)1: BSc, MSc in Clinical Midwifery, Lecturer, Hawassa University, College of Medicine and Health Sciences, School of Nursing and Midwifery, P.O. Box:-1560, Hawassa, Ethiopia, +251917093718, negashwakgari@yahoo.com

(FT)2: MD, MSc in Pharmacology, Assistant Professor, College of Medicine and Health Sciences, School of Medicine. P.O. Box:-1560, Hawassa, Ethiopia, +251911820354, fiker_taddesse@yahoo.com

\section{References}

1. Rehm J, Rehn N, Room R, Monteiro M, Gmel G, Jernigan D, Frick U. The Global Distribution of Average Volume of Alcohol Consumption and Patterns of Drinking. European Addiction Research 2003;9:147-156.

2. Tesfaye T, Byass P, Berhane Y, Bonita R, Wall S. Association of Smoking and Khat (Catha edulis Forsk) Use With High Blood Pressure Among Adults in Addis Ababa, Ethiopia, 2006. Public Health Research, Practice, And Police 2008;5(3):1 -11

3. World Health Organization. Global strategy to reduce harmful use of alcohol 2010 [cited 2016 July 29]. Available from: http://www.who.int/substance_abuse/alcstratenglishfinal.pdf?ua=1

4. Beaglehole R, Bonita R: Alcohol: a global health priority. Lancet 2009;373(9682):2173 -2174.

5. Cook R, Clark D: Is there an association between alcohol consumption and sexually transmitted diseases? A systematic review. Sex Transm Dis 2005; 32:156- ;164. PubMed

6. Krikorian A: Khat and its use: a historical perspective. J Ethnopharmacol 1984; 12:115- ;178.

7. Ageely HM: Health and socio-economic hazards associated with khat consumption. I Fam Community Med 2008; 15(1):3-11.

8. Rahim BEA, Yagoub U, Mahfouz MS, Solan
YMH, Alsanosi R: Abuse of selected psychoactive stimulants: overview and future research trends. Life Sci J 2012; 9(4):2295-2308.

9. Dawit A, Asfaw D, Amare D: Khat chewing habit as a possible risk behavior for HIV infection. Ethiop J Health Dev 2005; 19(3):174 -181.

10. Almotareb A, Baker K, Broadley K: Khat: Pharmacological and medical aspects and its social use in Yemen, a review article. Phytother Res 2002;16:403- 413.

11. Ayalu A, Asmamaw M, Sibhatu B, Berhanu Y: Prevalence and determinantsof Khat (Catha edulis) chewing among high school students in eastern Ethiopia: A cross- sectional study. PLoS one 2012; 7(3):33946 .

12. Ali AA, Al-Sharabi AK, Aguirre JM, Nahas R: A study of 342 oral keratotic white lesions induced by qat chewing among 2500 Yemeni. J Oral Pathol Med 2004; 33:368;372

13. Kassim S, Croucher R: Khat chewing amongst UK resident male Yemeniadults: an exploratory study. Int Dent J 2006; 56(2):97 -101

14. Gelaye B, Philpart M, Goshu M, Berhane Y, Fitzpatrick AL, Williams MA: Anger expression, negative life events and violent behaviour among male college students in Ethiopia. Scand J Public Health 2008; 2006(36):538-545.

15. Derege Kebede, Atalay Alem, Getnet Mitike, Fikre Enquselassie, Frehiwot Berhane, Yigeremu Abebe, Reta Ayele, Wuleta Lemma, Tamrat Assefa and Tewodros Gebremichael. Khat and alcohol use and risky sex behaviour among in-school and out-of-school youth in Ethiopia. BMC Public Health 2005;5(109).

16. Malaju MT, Asale GA. Association of Khat and alcohol use with HIV infection and age at first sexual initiation among youths visiting HIV testing and counseling centers in Gamo-Gofa Zone, South West Ethiopia. BMC International Healthand Human Rights 2013;13(10):1-8.

17. Kebede Y. Cigarette smoking and khat chewing among College students in North west Ethiopia. Ethiop J Health Dev 2002;16(1):9-17

18. Forrester K, Biglan A, Severson HH, Smolkowski K: Predictors of smoking onset over two years. Nicotine Tob Res 2007; 9:1259- 1267

19. Fidler JA, West R, van Jaarsveld CH, Jarvis MJ,Wardle $\mathrm{J}$ : Smoking status of step-parents as a risk factor for smoking in adolescence. Addiction 2008;103:496- 501

20. Madarasova Geckova A, Stewart R, van Dijk JP, Orosova O, Groothoff JW, Post D: Influence of socio-economic status, parents and peers on smoking be-

African Health Sciences Vol 16 Issue 3, September 2016 
haviour of adolescents. Eur Addict Res 2005; 11:204-209 21. Wakgari D, Aklilu A: Substance use and its predictors among undergraduate medical 361 students of Addis Ababa University in Ethiopia. BMC Public Health 2011; 11:660

22. Oshodi O, Aina O, Onajole A: Substances use among secondary school students in an 364 urban setting in Nigeria: prevalence and associated factors. African J 365 Psychiatry 2010; 13:32-57

23. Atwoli L, Mungla PA, Ndung'u MN, Kinoti KC, Ogot EM: Prevalence of substances use 337 among college students in Eldoret, western Kenya. BMC Psychiatry 2011; $11: 34$

24. Peltzer K, Malaka DW, Phaswana N: PsychologicalCorrelates of Substance Use among 367 South African University Students. Social Behaviour and Personality 2001;29:799-806.

25. Derese A, Seme A, Misganaw C. Assessment of substance use and risky sexual behaviour among Haramaya University Students, Ethiopia. Science Journal of Public Health 2014;2(2):102 -10.

26. Zein ZA. Polydrug abuse among Ethiopian university students with particular reference to khat (Catha edulis). J Trop Med Hyg 1998;91(2):71-5

27. Mahfouz MS, Alsanosy RM, Gaffar AM. The role offamily background on adolescent khat chewing behavior in Jazan Region. Annals of General Psychiatry 2013;12:16.

28. Alsanosy RM, Mahfouz MS, Gaffar AM. Khat Chewing among Students of Higher Education in Jazan Region, Saudi Arabia: Prevalence, Pattern, and
Related Factors. Hindawi Publishing Corporation 2013:7 29. Ageely HM. Prevalence of Khat chewing in college and secondary (high) school students of Jazan region, Saudi Arabia. Harm Reduction Journal 2009;6:11

30. Zein A. Poly drug abuse among Ethiopian University students with particular reference to khat (catha edulis). American Journal of Tropical Medicine and Hygiene 1998;91:15 .

31. Reda AA, Moges A, Wondmagegn BY, Biadgilign BS.Alcohol drinking patterns among high school students in Ethiopia: a cross-sectional study BMC Public Health Submit 2012;12:213

32. Greenbaum PE, Del Boca FK, Wang C, Goldman MS. Variation in the drinking trajectories of freshman college students. Journal of Consultingand Clinical Psychology 2005;73:229-38

33. Sessa FM. The influence of perceived parenting on substance use during the transition to college: Acomparison of male residential and commuter students. Journal of College Student Development 2005;46:6274

34. Gelaw Y, Haile-Amlak A. Khat chewing and its sociodemographic correlates among the staff of Jimma University. Ethiop J Health Dev 2004;18(3).

35. Alsanosy RM, Mahfouz MS, Gaffar AM. Khat Chewing Habit among School Students of Jazan Region, Saudi Arabia PLOS ONE 2013; 8(6):1-7

36. Kebede Y. Cigarette Smoking and Khat chewing among University instructors in Ethiopia. East African Medical Journal 2002;79(5):274-8 